Copyright (C) 2015 by Academic Publishing House Researcher

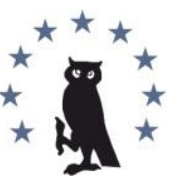

Published in the Russian Federation

European Researcher

Has been issued since 2010.

ISSN 2219-8229

E-ISSN 2224-0136

Vol. 92, Is. 3, pp. 214-221, 2015

DOI: 10.13187/er.2015.92.214

www.erjournal.ru

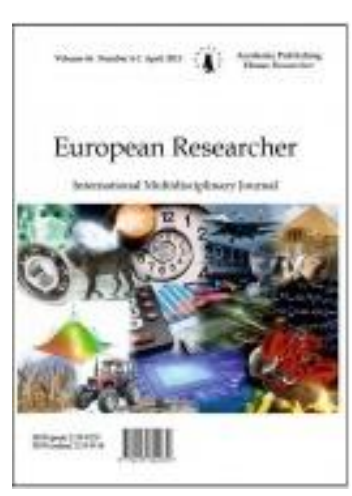

UDC 378.147.88 (574)

\title{
Organizing Independent Student Work
}

\author{
Zhadyra T. Zhumasheva
}

Kazakh National Resarch Technical University named after Kanysh I. Satpayev, Kazakhstan

Satpayev street 22, Almaty city, 050013

$\mathrm{PhD}$, Associate Professor

E-mail: Zhadyra_14@mail.ru

\begin{abstract}
This article addresses issues in organizing independent student work. The author defines the term "independence", discusses the concepts of independent learner work and independent learner work under the guidance of an instructor, proposes a classification of assignments to be done independently, and provides methodological recommendations as to the organization of independent student work. The article discusses the need for turning the student from a passive consumer of knowledge into an active creator of it, capable of formulating a problem, analyzing the ways of solving it, coming up with an optimum outcome, and proving its correctness. The preparation of highly qualified human resources is the primary condition for boosting Kazakhstan's competitiveness. Independent student work is a means of fostering the professional competence of future specialists. The primary form of self-education is independent work.

Keywords: independent learner work; independent student work; independent learner work under the guidance of an instructor; credit system of education; independence; selforganization; self-education; individuality; forms of conducting; self-development.

\section{Введение}

Новые условия развития казахстанского общества ставят перед системой высшего образования новые приоритеты. В качестве первоочередного направления выдвигается задача формирования качественно нового уровня подготовки будущих специалистов, обладающих собственным стилем мышления и оригинальным подходом к решению поставленных задач. Поэтому, целью Государственной программы развития образования Республики Казахстан на 2011-2020 годы является повышение конкурентоспособности образования, развитие человеческого капитала путем обеспечения доступности качественного образования для устойчивого роста экономики [1].

Внедрение кредитной технологии обучения в систему образования Республики Казахстан направлено на повышение качества образования и интеграцию в мировое образовательное пространство. Переход на кредитную систему обучения повышает роль самостоятельной работы обучающихся как одну из ведущих форм учебной деятельности. В соответствии с государственными общеобязательными стандартами высшего образования каждый академический час лекционных, практических (семинарских) и студийных занятий
\end{abstract}


обязательно сопровождается 2 часами (100 минут) самостоятельной работы студентов бакалавриата [2]. Самостоятельная работа обучающегося (СРО) определяется правилами организации учебного процесса по кредитной технологии обучения как "работа по определенному перечню тем, отведенных на самостоятельное изучение, обеспеченных учебно-методической литературой и рекомендациями, контролируемая в виде тестов, контрольных работ, коллоквиумов, рефератов, сочинений и отчетов»; в зависимости от категории обучающихся она подразделяется на самостоятельную работу студента (СРС), самостоятельную работу магистранта (CРM) и самостоятельную работу докторанта (СРД); весь объем СРО подтверждается заданиями, требующими от обучающегося ежедневной самостоятельной работы [3].

При кредитной технологии обучения самостоятельная работа обучающихся подразделяется на две части: на самостоятельную работу, которая выполняется под руководством преподавателя, и на ту часть, которая выполняется полностью самостоятельно.

Самостоятельная работа обучающегося под руководством преподавателя (СРОП) внеаудиторная работа обучающегося под руководством преподавателя, проводимая по утвержденному графику; в зависимости от категории обучающихся она подразделяется на: самостоятельную работу студента под руководством преподавателя (СРСП), самостоятельную работу магистранта под руководством преподавателя (СРМП) и самостоятельную работу докторанта под руководством преподавателя (СРДП).

СРОП является внеаудиторным видом работы обучающихся, которая выполняется им в контакте с преподавателем. СРОП выполняется по отдельному графику, который не входит в общее расписание учебных занятий.

В СРОП входят консультации по наиболее сложным вопросам учебной программы, выполнению домашних заданий, курсовых проектов (работ), контроль семестровых работ, отчетов и других видов заданий СРО.

При кредитной технологии обучения увеличивается объем выполняемой студентами самостоятельной работы. Задача кредитной технологии обучения состоит в развитии у студентов способностей к самоорганизации и самообразованию. Соответственно реализуются следующие типовые циклы работы преподавателя и студентов.

1) Типовой единичный цикл работы преподавателя со студентами (РПС) включает следующие три основные функции.

Первая функция преподавателя - установочная (введение в тему, постановка цели, задач, описание практической полезности, сущности и взаимосвязи основных разделов содержания материала, рекомендаций по работе с учебно-методическими пособиями и др.). Этого должно быть достаточно для дальнейшей самостоятельной работы студентов.

Вторая функция преподавателя - консультативно-корректировочная. Она состоит в оказании консультативной помощи в реализации учебных действий в самостоятельной работе студентов, проведении индивидуальных консультаций и осуществлении соответствующих корректировочных действий. Данную функцию в образовательном процессе выполняют тьюторы.

Третья функция преподавателя - контрольно-оценочная. Она предполагает проведение оценивания знаний, умений и навыков студентов в различных формах (письменный или устный экзамен, тестирование и др.), организацию диалога по выявлению их основных затруднений, демонстрацию преподавателем «правильных» действий, взаимодействия, эталонных способов работы в позиции эксперта или контролера.

2) Типовой единичный цикл самостоятельной работы студентов под руководством преподавателя (СРСП) включает следующие четыре основные функции.

Первая - предполагает реализацию активного восприятия студентами информации преподавателя, полученной в период установочных занятий по учебной дисциплине.

Вторая функция предполагает, что студенты самостоятельно, на основании рекомендаций преподавателя, изучают учебно-методические пособия, литературные источники, выполняют домашние задания, контрольные и курсовые работы и т.д. На этом этапе от студентов требуется знание методов работы, фиксация своих затруднений, самоорганизация и самодисциплина. 
Третья функция студентов состоит в анализе и систематизации своих затруднительных ситуаций, выявлении причин затруднений в понимании и усвоении ими учебного материала, выполнении других учебных действий. Студенты переводят неразрешимые затруднения в систему вопросов для преподавателя (ранжируют их, упорядочивают, оформляют), строят собственные версии ответов на эти вопросы.

Четвертая функция студентов состоит в обращении к преподавателю за соответствующими разъяснениями, советами, консультациями.

\section{Материалы и методы}

Понятие «самостоятельность» означает систему навыков сознательной самоорганизации. Под самостоятельной работой студента подразумевают вид учебного труда, который призван, наряду с формированием знаний, умений и навыков, развивать систему навыков личностной самоорганизации. В процессе самостоятельной работы студент должен приобрести следующие умения: а) понять текст; б) вычленить и переосмыслить постановки типовых заданий и рациональные образцы деятельности; в) составлять на базе анализа учебных текстов теоретические и практические построения.

Организационные формы самостоятельной работы обычно связывают с работой в библиотеке, а также с электронными ресурсами для выполнения ознакомительной работы, анализа научной литературы по данной дисциплине, патентно-информационного поиска, реферирования, написания отчетов. Однако существует необходимость построения обоснованной системы СРС, которая должна базироваться на разработке задач и заданий; подборе литературы для самостоятельного изучения, учитывающем различные точки зрения на проблему; разработке вопросов для самопроверки. Организация такой системы строится на побуждении исследовательского интереса, формировании мотивов к устойчивому, глубокому овладению знаниями, преодолении трудностей. Это возможно при обеспечении поэтапного процесса усвоения знаний, без перескакивания на более высокий уровень сложности, не овладев низким.

Отдельно выделяют самостоятельную исследовательскую деятельность как познавательную деятельность студента, которую он совершает индивидуально без указаний преподавателя, руководствуясь только сформулированными ранее представлениями о порядке и правильности выполнения операций и действий. Процесс самостоятельной исследовательской деятельности предполагает интеллектуальную активность, осознанность исследовательских действий и определенный уровень научных знаний студентов.

Давая задания для самостоятельной работы, целесообразно разделять их на уровни сложности, составляя для каждого уровня алгоритмы выполнения определяющие последовательность учебных действий по признаку самостоятельности. Способность самостоятельно выполнять задания каждого уровня характеризует успешность овладения необходимыми знаниями и умениями. По способности решать разноуровневой сложности задачи; проводить исследования и научные эксперименты; использовать знания и создавать новую информацию на базе усвоенной; создавать схемы, модели, технологические цепочки; генерировать творческие идеи - можно судить о самостоятельности студента.

Особая роль заданий на самостоятельное выполнение заключается в целенаправленности содержания. Для успешной самостоятельной работы студенту необходимо осознать и принять цель работы при выполнений заданий каждого уровня. Важно четко представлять способы достижения этой цели. На низких уровнях сложности предлагаются задания, выполнение которых осуществляется на основании теоретического материала, изложенного в рекомендуемой учебно-методической литературе. При выполнении этих заданий студент проясняет смысл новых понятий. На высоких уровнях сложности составленные задания содержат в себе конкретную проблему изучаемой области, решение которой требует широкого использования имеющихся знаний и умений. В ходе выполнения таких заданий предусматривается возможность использования экспериментальных методов исследования определенных технических явлений с объяснением получаемых данных и их обработкой. В результате студент привлекается к решению реальных научно-технических проблем, ощущая себя исследователем.

Таким образом, СРС может строиться на основе предварительно разработанной классификации заданий на самостоятельное решение (таблица), включающей в данном 
случае четыре уровня сложности. Это значит, что формулировка заданий разной сложности осуществляется на четырехуровневой основе иерархического процесса усвоения знания [4]. Соответственно, рассматриваются четыре типа самостоятельных работ.

Таблица. Классификация заданий на самостоятельное выполнение

\begin{tabular}{|c|c|c|c|}
\hline $\begin{array}{c}\text { № } \\
\Pi / \Pi\end{array}$ & Уровень сложности & Преследуемые цели & Содержание заданий \\
\hline 1 & $\begin{array}{l}\text { I-первый уровень } \\
\text { сложности, } \\
\text { соответствует } \\
\text { «знаниям } \\
\text { знакомства» } \\
\end{array}$ & $\begin{array}{l}\text { Научиться узнавать } \\
\text { объект изучения. Уметь } \\
\text { понять задачу, ее } \\
\text { конкретизировать, } \\
\text { формализовать. } \\
\end{array}$ & $\begin{array}{l}\text { Описание явлений, распознавание } \\
\text { механизма процессов, } \\
\text { формулировка определений, } \\
\text { изложение теоретических } \\
\text { положений. }\end{array}$ \\
\hline 2 & $\begin{array}{l}\text { II-второй уровень } \\
\text { соответствует } \\
\text { «Знаниям копии» }\end{array}$ & $\begin{array}{l}\text { Воспроизводить по } \\
\text { памяти усвоенную } \\
\text { информацию и решать } \\
\text { типовые задачи. } \\
\text { Находить и переносить } \\
\text { нужную информацию. }\end{array}$ & $\begin{array}{l}\text { Уяснение методов применения } \\
\text { теоретических знаний к решению } \\
\text { типовых задач, постижение } \\
\text { логики исследовательских } \\
\text { действий. }\end{array}$ \\
\hline 3 & $\begin{array}{l}\text { III-третий уровень } \\
\text { «заниям умения» }\end{array}$ & $\begin{array}{l}\text { Решать нетиповые задачи } \\
\text { прибегая к обобщению. } \\
\text { Менять тактику действий } \\
\text { в соответствии с изме- } \\
\text { нившейся задачей. }\end{array}$ & $\begin{array}{l}\text { Построение графических } \\
\text { зависимостей, расчет значений } \\
\text { свойств и характеристик, } \\
\text { переформулировка сущностных } \\
\text { понятий. }\end{array}$ \\
\hline 4 & $\begin{array}{l}\text { VI-четвертый } \\
\text { уровень «знаниям } \\
\text { трансформации» }\end{array}$ & $\begin{array}{l}\text { Генерировать идеи. } \\
\text { Иметь системность } \\
\text { представлений в дан-ной } \\
\text { области знаний. Уметь } \\
\text { формулиро-вать и } \\
\text { переформули- } \\
\text { ровать задачу. }\end{array}$ & $\begin{array}{l}\text { Создание системы осознанных } \\
\text { приемов и методов исследования, } \\
\text { постановка и разрешение } \\
\text { проблемы с помощью общих и } \\
\text { конкретных подходов к решению } \\
\text { задач в данной области. }\end{array}$ \\
\hline
\end{tabular}

К первому типу отнесены те самостоятельные работы, в которых преследуется цель формировать у студентов умений выявлять то, что от них требуется на основе данного им алгоритма деятельности и посылок на эту деятельность, содержащихся в условиях задания. Самостоятельная исследовательская деятельность студентов заключается в узнавании объектов изучения при повторном восприятии информации о них или повторных действиях с ними.

Цель самостоятельных работ второго типа заключается в формировании знаний и деятельности, позволяющих воспроизводить по памяти усвоенную информацию и решать типовые задачи. Самостоятельная исследовательская деятельность студентов, в том случае, заключается в четком воспроизведении или частичном реконструировании, преобразовании структуры и содержания усвоенной ранее информации. Это предполагает необходимость анализировать данное описание объекта изучения, различные возможные пути выполнения задания, выбирать наиболее правильные из них или последовательно находить логически следующие друг за другом способы решения.

Самостоятельные работы третьего типа имеют целью: формирование у студентов знаний и умений, лежащих в основе решения нетиповых задач. Самостоятельная исследовательская деятельность студентов при выполнении самостоятельных работ этого типа заключается в накоплении и проявлении нового для них опыта на базе усвоенного ранее формализованного опыта (опыта действий по известным алгоритмам) путем осуществления переноса знаний, умений и навыков. Такая деятельность сводится к поиску, формулированию и реализации способа решения, что требует выхода за пределы прошлого формализованного опыта и заставляет студентов варьировать условиями задачи и усвоенной ранее информацией, рассматривать их под новым углом зрения. 
Цель самостоятельных работ четвертого типа - создание предпосылок для творческой деятельности. Познавательная деятельность обучаемых здесь заключается в глубоком проникновении в сущность рассматриваемых объектов, установлении новых связей и отношений, необходимых для нахождения новых, неизвестных ранее идей и принципов решений, генерирования новой информации. Это требует на каждом этапе работы задумываться над сущностью новых целей и новых действий, над характером той информации, которую следует создавать.

Таким образом, построение системы задач и заданий возрастающей сложности на основе представления содержания дисциплины связано прежде всего, с возможностями или степенями их усвоения. Только постепенно вводя в учебный процесс учебные задачи разного уровня сложности, возможно прийти к активизации познавательной деятельности осмысленному восприятию изучаемого материала, формированию умственных операций по анализу, синтезу, сравнению, обобщению.

Одним из важнейших условий эффективной организации самостоятельной работы студентов в условиях кредитной системы обучения является педагогически целесообразное определение необходимого уровня сложности заданий [5]. Данный элемент зависит от курса обучения студентов, что определяет целевую направленность СРС. Так, на 1-2 курсах СРС ставит целью расширение и закрепление знаний и умений, получаемых на лекциях и семинарах. В этом случае наиболее эффективными будут следующие формы проведения CPC [6]:

1. Написание эссе-формулировка какого-либо понятия;

2. Обзор по теме - письменно написать краткий литературный обзор, по рекомендуемой теме с привлечением дополнительного материала из печати и электронных ресурсов;

3. Написание глоссария - краткое разъяснение терминов и понятий по заданной теме, можно заменить кроссвордом;

4. Реферат - это краткое изложение основного содержания статьи или какого-то труда, которое в отличие от конспекта составляется не для себя, а для освещения заданной темы, с целью представления или выступления перед слушателями.

На старших курсах СРС должна способствовать развитию творческого потенциала студента и реализации профессиональных навыков. В данном случае задания могут носить как индивидуальный, так и групповой характер, в силу того, что реальные профессиональные условия в большинстве случаев основаны на работе в коллективе:

1. Презентация - выбор студентом определенной темы для презентации и выражение своего видения, понимания или непонимания какого-либо аспекта, рассматриваемого в презентации. Время презентации 8-10 мин., оценивается презентация по критерию степени раскрытия темы, степени интереса, вызванного у слушателей, профессионализму;

2. Деловая игра - ролевая или командная, вырабатывающая для будущей профессиональной деятельности. Иногда требует домашней подготовки или завершения в библиотеке;

3. Конкретная учебная ситуация, требующая ответов студента на вопросы по ней или написания своего видения проблемы;

4. Групповой проект - в группе должно быть не более 4-5 человек, каждая группа разрабатывает свой проект;

5. Научный реферат - содержит необходимые элементы научного исследования (цель работы, проблему исследования, методы исследования, выводы).

\section{Обсуждения}

Кредитная технология предусматривает индивидуализацию обучения, и как следствие, требует более высокой качественной значимости самостоятельной работы студентов. СРС предполагает выполнение заданий по каждой теме дисциплины.

Систематизация самостоятельных работ может быть проведена по целям; по характеру учебных задач, решаемых студентом; по характеру учебной деятельности, необходимой для решения различных задач и т.п.

Важное место в самостоятельной работе занимает работа с учебно-методической литературой, осуществляемая как в начальный период, так и на период самоорганизации. 
Здесь следует включать в рекомендуемый перечень литературы основные учебники и учебные пособия по изучаемой дисциплине, а также новые источники научно-технических сведений. При этом необходимы указания конкретных разделов и страниц ориентировки студента на нужный материал.

Рассмотрим основные формы организации СРС, использование которых способствует повышению эффективности данного компонента учебной деятельности студентов. СРС включает выполнение домашних заданий, таких как реферат, доклад, очерк, кейс, кроссворд, решение задач, упражнений, выполнение графических работ, проведение расчетов и т.п. направленных на развитие у студентов самостоятельности и инициативы. Для этого преподаватель должен своевременно обеспечить студентов заданиями и рекомендациями по их выполнению. Очень важно, чтобы соблюдалась ритмичность в течение семестра [7].

С учетом вышесказанного, для эффективного планирования и организации СРС студентов в условиях кредитной системы обучения необходимо:

- обеспечить учебно-методическую поддержку и индивидуальность заданий на самостоятельную работу студентов;

- выдать задания СРС в начале учебного года (семестра);

- разработать текущий и рубежный формы контроля;

- установить время консультаций по СРС/СРСП.

\section{Результаты}

Самостоятельное овладение определенными знаниями и умениями в результате самостоятельной деятельности развивает творческие силы студента. Поэтому, важно, наряду с широтой и глубиной усвоения уже готовых форм, обеспечивать рост уровня творчества в учебно-исследовательской деятельности студентов на основе признака самостоятельности или способности к самостоятельной деятельности. Для инициирования самостоятельной творческой деятельности студентов необходимо создать условия. От организации активного и самостоятельного изучения каждым студентом учебного материала зависит эффективность учебного процесса.

В результате самостоятельного овладения конкретными знаниями и умениями студенты способны впоследствии творчески решать профессиональные задачи разной сложности.

К самостоятельному приобретению новых знаний, пополнению и совершенствованию своего образования приводит овладение основами теории и методами исследований, а также алгоритмами решения типовых задач. При этом студенту необходимо помочь самостоятельно:

- осознать общее содержание и направление своей работы;

- изучить и понять взаимосвязь положений теории, системы понятий, моделей, методов и практических действий по решению типовых задач;

- осознать и запомнить основные, фундаментальные положения и выводы теории и типовые алгоритмы деятельности;

- убедиться в прочности и глубоком овладении запланированными знаниями и умениями посредством адекватного применения усвоенных знаний для решения различных вариантов задач;

- изучить, понять, запомнить и активизировать методы проверки правильности решения и достоверности результатов решения изучаемых задач и способов деятельности.

В результате студент осознает значимость изучаемой дисциплины.

Главное в организации самостоятельной работы обеспечить механизм управления процесса усвоения знаний в ходе самостоятельного поиска. Систематическое решение научно-исследовательских заданий разного типа и уровни сложности является самым эффективным способом обучения.

\section{Заключения}

Главное в стратегической линии организации самостоятельной работы студентов в условиях внедрения кредитной технологии заключается в создании условий высокой 
активности, самостоятельности и ответственности студентов в аудитории и вне ее в ходе всех видов учебной деятельности.

Ведущим механизмом при самостоятельной работе является: самостоятельный анализ - самостоятельный выбор - самостоятельная постановка цели - самостоятельное проектирование - самостоятельная реализация выбранной стратегии - самостоятельная коррекция.

Таким образом, основным принципом организации СРС должен стать перевод всех студентов на индивидуальную работу, с формированием собственного мнения при решении поставленных проблемных вопросов и задач. Следовательно, СРС способствует формированию профессиональной компетенции будущего специалиста $[8,9,10]$.

\section{Примечания:}

1. Государственная программа развития образования Республики Казахстан на 20112020 годы. Утверждена Указом Президента Республики Казахстан от 7 декабря 2010 года №1118.

2. Государственный общеобязательный стандарт образования. Государственный общеобязательный стандарт высшего образования. Утвержден постановлением Правительства Республики Казахстан от 23 августа 2012 года № 1080. Астана, 2012.

3. Правила организации учебного процесса по кредитной технологии обучения. Утверждены приказом Министра образования и науки Республики Казахстан № 152 от 20 апреля 2011 г.

4. Беспалько В.П. Слагаемые педагогической технологии. Москва: Педагогика, 1989. $190 \mathrm{c}$.

5. Чебышев Н., Каган В. Высшая школа XXI века: проблемы качества // Высшее образование. 2000. №1. С.19-26.

6. Организация, формы и методы проведения учебных занятий и самостоятельной работы: требования, условия, механизмы. Учеб. метод. пособ. / Под ред. Н.А. Волгина. М.: Рос. экон. акад., 2004. 88 с.

7. Демеуов А. Особенности планирования, организации и контроля внеаудиторной самостоятельной работы студентов // Высшая школа Казахстана. 2004. №3. С. 52-54.

8. Жұмашева Ж.Т. Болашақ маманның кәсіптік құзіреттілігін қалыптастыру // Труды Международного форума «Инженерное образование и наука в XXI веке: проблемы и перспективы», посвященного 80-летию КазНТУ имени К.И. Сатпаева в 3-х т. Алматы., 2014, T. II. C. $135-142$.

9. Жұмашева Ж.Т. «Мехатроника» курсын кредиттік жүйе бойынша оқытудың әдістемесі / Жұмашева Ж.Т. // Труды Международной научно-практической конференции «Информационно-инновационные технологии: интеграция науки, образования и бизнеса». Алматы, 2008. С. 507-509.

10. Жұмашева Ж.Т. «Робототехника және робототехникалық жүйелер» пәнін кредиттік технология бойынша оқыту / Жұмашева Ж.Т. // Тезисы докладов первого международного Джолдасбековского симпозиума. Алматы, 2011. С. 263.

\section{References:}

1. Gosudarstvennaya programma razvitiya obrazovaniya Respubliki Kazakhstan na 20112020 gody. Utverzhdena Ukazom Prezidenta Respubliki Kazakhstan ot 7 dekabrya 2010 goda №1118.

2. Gosudarstvennyi obshcheobyazatel'nyi standart obrazovaniya. Gosudarstvennyi obshcheobyazatel'nyi standart vysshego obrazovaniya. Utverzhden postanovleniem Pravitel'stva Respubliki Kazakhstan ot 23 avgusta 2012 goda № 1080. Astana, 2012.

3. Pravila organizatsii uchebnogo protsessa po kreditnoi tekhnologii obucheniya. Utverzhdeny prikazom Ministra obrazovaniya i nauki Respubliki Kazakhstan № 152 ot 20 aprelya $2011 \mathrm{~g}$.

4. Bespal'ko V.P. Slagaemye pedagogicheskoi tekhnologii. Moskva: Pedagogika, 1989. 190 s.

5. Chebyshev N., Kagan V. Vysshaya shkola XXI veka: problemy kachestva // Vysshee obrazovanie. 2000. №1. S. 19-26. 
6. Organizatsiya, formy i metody provedeniya uchebnykh zanyatii i samostoyatel'noi raboty: trebovaniya, usloviya, mekhanizmy. Ucheb. metod. posob. / Pod red. N.A. Volgina. M.: Ros. ekon. akad., 2004. $88 \mathrm{~s}$.

7. Demeuov A. Osobennosti planirovaniya, organizatsii i kontrolya vneauditornoi samostoyatel'noi raboty studentov // Vysshaya shkola Kazakhstana. 2004. №3. S. 52-54.

8. Zhłmasheva Zh.T. Bolashaқ таmannyң kəsiptik құzirettiligin қаlyptastyru // Trudy Mezhdunarodnogo foruma «Inzhenernoe obrazovanie i nauka v XXI veke: problemy i perspektivy», posvyashchennogo 8o-letiyu KazNTU imeni K.I. Satpaeva v 3-kh t. Almaty., 2014, T. II. S. 135-142.

9. Zhұmasheva Zh.T. «Mekhatronika» kursyn kredittik zhүie boiynsha окуtudyн әdistemesi / Zhymasheva Zh.T. // Trudy Mezhdunarodnoi nauchno-prakticheskoi konferentsii «Informatsionno-innovatsionnye tekhnologii: integratsiya nauki, obrazovaniya i biznesa». Almaty, 2008. S. 507-509.

10. Zhłmasheva Zh.T. «Robototekhnika zhəne robototekhnikalyқ zhүieler» pənin kredittik tekhnologiya boiynsha окуtu / Zhłmasheva Zh.T. // Tezisy dokladov pervogo mezhdunarodnogo Dzholdasbekovskogo simpoziuma. Almaty, 2011. S. 263.

УДК 378.147.88 (574)

\title{
Организация самостоятельной работы студентов
}

\author{
Жадыра Токановна Жумашева
}

Казахский национальный исследовательский технический университет имени

К.И. Сатпаева, Казахстан

050013, г. Алматы, ул. Сатпаева, 22

Кандидат технических наук, доцент

E-mail: Zhadyra_14@mail.ru

Аннотация. В статье рассмотрены проблемы организации самостоятельной работы студентов. Приведены определения понятий «самостоятельность», самостоятельной работы обучающегося и самостоятельной работы обучающегося с преподавателем, а также классификация заданий на самостоятельное выполнение. Даны методические рекомендации к организации самостоятельной работы студентов. В статье предлагается о необходимости перевести студента из пассивного потребителя знаний в активного его творца, умеющего сформулировать проблему, проанализировать пути ее решения, найти оптимальный результат и доказать его правильность. Подготовка высококвалифицированных кадров является главным условием повышения конкурентоспособности Казахстана. Самостоятельная работа студента как средство формирования профессиональной компетенции будущего специалиста. Основной формой самообразования является самостоятельная работа.

Ключевые слова: самостоятельная работа обучающегося; самостоятельная работа студента; самостоятельная работа обучающегося под руководством преподавателя; кредитная система обучения; самостоятельность; самоорганизация; самообразование; индивидуальность; формы проведения; саморазвитие. 